\title{
PERBANDINGAN KUALITAS AIR MATA ANTARA PENGGUNA DAN NON PENGGUNA LENSA KONTAK
}

\author{
Arief Witjaksono $^{1)}$, Ranie Khairunnisa ${ }^{2)}$ \\ 1,2 Program Studi Diploma Tiga Refraksi Optisi STIKes Dharma Husada \\ awicaksono2403@gmail.com
}

\begin{abstract}
COMPARISON OF EYE QUALITY BETWEEN USERS AND NON USERS CONTACT LENS

The use of contact lenses can cause dry eyes, it is caused by mechanical irritation of the meibomian gland. The meibomian gland produces a layer of fat which functions to inhibit evaporation of the tear layer. Disruption of the function of the meibomian gland causes the tear layer to evaporate quickly. Contact lenses also reduce the sensitivity of the eye surface so that the tear layer production reflex decreases. Increased evaporation accompanied by a decrease in tear production causes most contact lens users to experience dry eyes. The purpose of this study is to find out the difference in the quality of tears between users and non-contact lens users. Case control design with observational techniques has been conducted. This study used a schirmer test and observational sheet. The results of the study showed that of the 20 active contact lens users 14 (70.0\%) had dry eyes and 3 (15.0\%) of 20 noncontact lens users had dry eyes. Statistically Independent T-Test $r=0.00<0.005$ there is a difference between the quantity of tears of users and non contact lens users. It is recommended to pay attention to the use of contact lenses for long usage, usage period and lubricant on contact lenses so as not to cause complications in the use of contact lenses and dry eyes.
\end{abstract}

Keywords: Tear quality, Users, Contact lenses

\begin{abstract}
ABSTRAK
Penggunaan lensa kontak dapat menyebabkan mata kering, hal itu disebabkan oleh iritasi mekanik terhadap kelenjar meibomian. Kelenjar meibomian menghasilkan lapisan lemak yang berfungsi menghambat penguapan lapisan air mata. Gangguan fungsi kelenjar meibomian menyebabkan lapisan air mata cepat menguap. Lensa kontak juga menurunkan sensitivitas permukaan mata sehingga refleks produksi lapisan air mata menurun. Peningkatan penguapan disertai penurunan produksi lapisan air mata menyebabkan sebagian besar pengguna lensa kontak mengalami mata kering. Tujuan Penelitian ini yaitu Untuk mengetahui Perbedaan Kualitas Air Mata Antara Pengguna Dan Non Pengguna Lensa Kontak. Metode penelitian yang digunakan adalah menggunakan desain case control dengan teknik observasional. Penelitian ini menggunakan tes schirmer dan lembar observasional. Hasil penelitian yang di dapat bahwa dari 20 orang pengguna aktif lensa kontak sebanyak 14 (70,0\%) orang mengalami mata kering dan dari 20 orang non pengguna lensa kontak sebanyak $3(15,0 \%)$ orang mengalami mata kering. Secara statistik Uji-T Independen $r=0.00<0.005$ terdapat perbedaan antara kuantitas air mata pengguna dan non pengguna lensa kontak. Disarankan agar memperhatikan penggunaan lensa kontak pada lama pemakaian, masa pemakaian serta lubrikan pada lensa kontak agar tidak menimbulkan komplikasi pemakaian lensa kontak dan mata kering.
\end{abstract}

Kata Kunci : Kualitas air mata, Pengguna, Lensa kontak 


\section{PENDAHULUAN}

Mata juga merupakan indra terpenting dalam kehidupan manusia agar dapat melakukan aktivitas sehari-hari dengan baik (Pietersz, Sumual dan Rares,2014). Akan tetapi, ada banyak faktor yang menyebabkan terjadinya penurunan penglihatan, sehingga diharuskan seseorang menggunakan alat bantu untuk melihat. Salah satunya adalah lensa kontak (Utami, Nukman, dan Azrin,2016).

Pada hasil Riskesdas 2013 di Indonesia terdapat $4,6 \%$ penduduk yang menggunakan lensa kontak dan proporsi penduduk yang menggunakan lensa kontak di daerah provinsi Jawa Barat 4,8\%. Sedangkan pada hasil proporsi penduduk Indonesia yang menggunakan lensa kontak di perkotaan 6,6\% dan di perdesaan 2,6\%. Selain itu, berdasarkan jenis kelamin penduduk perempuan $(5,0 \%)$ cenderung lebih banyak menggunakan lensa kontak dibandingkan penduduk laki-laki (4,3\%) (Riskesdes,2013).

Penelitian yang dilakukan Sinaga dan Wahdini pada mahasiswa tingkat III FKUI yang berjumlah 244 orang untuk mengetahui berapa jumlah pengguna lensa kontak dan persentase pengguna lensa kontak dalam penelitian ini adalah $13,8 \%$. Banyak di antara mereka yang awalnya menggunakan kaca mata beralih ke lensa kontak karena pemakaiannya lebih mudah, sederhana dan juga mendukung penampilan (Sinaga dan Wahdini,2014).

Menurut Stanler, sekitar 80.000 pengguna lensa kontak menderita penyakit mata, khususnya gangguan pada konjungtiva, kornea dan kalenjar air mata (Wakarie dan Rares, 2014). Pengguna lensa kontak berpotensi terinfeksi bakteri, jamur, atau mikroba lainnya apabila digunakan tanpa memperhatikan aspek kebersihan dan petunjuk penggunaan. Menurut salah satu dokter spesialis mata dari RSUD dr Soetomo, yaitu Hendrian D. Soebagyo., Sp.M menyatakan, sekitar $50 \%$ pasien mengalami gangguan mata karena lensa kontaknya terkontaminasi oleh amoeba, dan $1 \%$ diantaranya mengalami gangguan berat hingga menyebabkan kebutaan permanen (Sunarti dan Setianingsih,2017).

Penelitian yang dilakukan oleh Pietersz, Sumual dan Rares di Universitas Sam Ratulangi, didapatkan hasil penelitian berdasarkan distribusi frekuensi responden dengan dry eyes sebanyak 16 orang $(53,3 \%)$ (Pietersz, Sumual dan Rares,2016). Dalam penelitian yang dilakukan oleh Sunarti dan Wahyu diketahui $54.3 \%$ pengguna lensa kontak tidak menggunakan SOP, hal ini menjadi salah satu penyebab terjadinya gangguan pada mata (Sunarti dan Wahyu,2017).

Dari seluruh pemakai lensa kontak terdapat lebih dari $50 \%$ pemakai lensa kontak mengalami mata kering (Kaštelan 
dan Riley dalam Gultom,2017). Menurut Rumpakis (2010) sebanyak 16-30\% orang berhenti memakai lensa kontak dengan alasan utama merasa tidak nyaman saat memakai lensa kontak dan mata kering. Tingginya angka kejadian mata kering akibat pemakaian lensa kontak menjadi perhatian serius baik untuk pemakai lensa kontak dan juga dokter (Gultom,2017).

Penggunaan lensa kontak dapat menyebabkan mata kering, hal itu disebabkan oleh iritasi mekanik terhadap kelenjar meibomian. Kelenjar meibomian menghasilkan lapisan lemak yang berfungsi menghambat penguapan lapisan air mata. Gangguan fungsi kelenjar meibomian menyebabkan lapisan air mata cepat menguap. Lensa kontak juga menurunkan sensitivitas permukaan mata sehingga refleks produksi lapisan air mata menurun. Peningkatan penguapan disertai penurunan produksi lapisan air mata menyebabkan sebagian besar pengguna lensa kontak mengalami mata kering (Sitompul dalam Syaqdiyah, Prihatningtias dan Saubig,2018).

Penelitian yang dilakukan oleh Syehabudin mengenai angka kejadian dry eye pada pengguna lensa kontak menggunakan Tes Schirmer secara objektif terdapat 39 mata $(72.2 \%)$ yang mengalami dry eyes. Dengan derajat keparahan yang berbeda-beda dari tingkat satu (46.3\%), tingkat dua $(20,4 \%)$, tingkat tiga $(11,1 \%)$ dan tingkat empat (22.2\%) (Syehabudin, 2017).

Berdasarkan penelitian yang dilakukan oleh Syaqdiyah dari 50 mata yang telah dilakukan pengukuran tes Schirmer, terdapat 12 mata $(24 \%)$ yang mengalami mata kering dan 38 mata (76\%) dengan produksi air mata normal. Lama pemakaian lensa kontak dan mata kering memiliki hubungan bermakna $(p=0,007)$ dengan kekuatan korelasi sedang $(r=-0,379)$ (Syaqdiyah, Prihatningtias dan Saubig,2018). Dari penelitian yang dilakukan oleh Hisan, jumlah siswa pemakai lensa kontak yang menderita $d r y$ eye syndrome sebanyak 50 siswa $(94,3 \%)$, sedangkan jumlah siswa bukan pemakai lensa kontak yang menderita dry eye syndrome sebanyak 29 siswa $(54,7 \%)$ (Hisan,2016).

Komplikasi yang dapat ditimbulkan dari penyakit mata kering antara lain adalah meningkatkan risiko terjadi infeksi mata akibat kekurangan pasokan air mata, kerusakan permukaan mata akibat kondisi mata kering yang dibiarkan tanpa pengobatan sehingga memicu konjungtivitis, kerusakan permukaan kornea, luka terbuka pada kornea, serta gangguan penglihatan. Sindrom mata kering juga menimbulkan kesulitan pada penderitanya dalam melakukan kegiatan sehari-hari, seperti membaca atau mengemudikan kendaraan (Willy,2018) 
Tujuan Penelitian adalah Untuk mengetahui Perbedaan Kualitas Air Mata Antara Pengguna Dan Non Pengguna Lensa Kontak. Penelitian ini diharapkan bermafaat agar masyarakat lebih memahami peran penting air mata pada pengguna lensa kontak serta bagi pengembangan keilmuan untuk analisis faktor risiko penggunaan lensa kontak terhadap mata kering.

\section{METODE PENELITIAN}

Penelitian ini menggunakan desain Case Control untuk menilai seberapa besar pengaruh faktor risiko dalam suatu masalah kesehatan dengan menggunakan pendekatan retrospective yaitu pengumpulan data dimulai dari akibat kemudian ditelusuri penyebabnya. Studi kasus kontrol dilakukan dengan mengidentifikasi kelompok kasus dan kontrol kemudian secara retrospective diteliti faktor-faktor risiko yang mungkin dapat menerangkan apakah kasus dan kontrol dapat terkena paparan atau tidak. Penelitian ini dilakukan secara observational untuk mengetahui perbedaan kualitas air mata antara pengguna dan non pengguna menggunakan tes schirmer dan tes ferning. Penelitian ini dilakukan pada bulan April hingga Mei 2019.

Populasi pada penelitian adalah semua pengguna aktif dan semua non pengguna lensa kontak. Kelompok case yaitu pengguna lensa kontak dan yang termasuk kelompok control yaitu non pengguna lensa kontak.

Teknik penentuan sampel adalah metode non probability sampling yaitu teknik pengambilan sampel yang tidak memberikan peluang atau kesempatan sama bagi setiap unsur atau anggota populasi untuk dipilih menjadi sampel, dengan menggunakan pendekatan purposive sampling karena tidak semua sampel memiliki kriteria sesuai dengan yang telah penulis tentukan. Sampel yang dipilih sengaja ditentukan berdasarkan kriteria tertentu yang telah ditentukan oleh penulis untuk mendapatkan sampel yang representatif.

Kriteri inklusi dalam penelitian adalah Pengguna aktif lensa kontak dengan minimal masa pemakaian lensa kontak 1 tahun, semua golongan umur, berjenis kelamin wanita, bertempat tinggal di Kota Bandung, bersedia menjadi responden. Sedangkan Kriteia eksklusi adalah mata dalam keadaan terinfeksi, pengguna RGP, jenis kelamin laki-laki

Instrumen penelitian ini berupa lembar observasi yang digunakan untuk mengukur pemakaian lensa kontak baik dari segi masa pakai dan lama pakai pada pengguna aktif lensa kontak

Pengumpulan data dilakukan secara langsung untuk mendapatkan data primer dari sampel penelitian dan sumber-sumber dasar yang terdiri dari bukti-bukti kejadian 
objek yang diteliti dan gejala yang terjadi dilapangan.

Pengukuran kadar dan kualitas air mata dilakukan dengan tes schirmer dan tes ferning. Pengguna lensa kontak ditentukan dalam 3 kategori, yaitu pengguna aktif, pengguna pasif, pengguna lensa kontak.

Analisa data yang digunakan berupa analisa univariat dan analisa bivariat. Analisis univariat bertujuan untuk menjelaskan atau mendeskripsikan karakteristik setiap variabel penelitian.
Dalam penelitian ini mendeskripsikan perbedaan kualitas air mata responden pada pengguna dan bukan pengguna lensa kontak terhadap dry eyes dan non dry eyes, setelah didapatkan total nilai dari semua item maka perbedaan kualitas air mata responden dapat diketahui dengan menggunakan rumus:

$$
\mathrm{P}=\frac{f}{n} \times 100 \%
$$

Analisa bivariat dalam penelitian ini menggunakan Uji $\mathrm{T}$ untuk membandingkan (membedakan) apakah kedua data (variabel) tersebut sama atau berbeda.

III.HASIL

Tabel 1 Distribusi Frekuensi Karakteristik Pengguna Lensa Kontak

\begin{tabular}{|c|c|c|c|c|c|c|}
\hline Kategori & $\begin{array}{l}\text { Mata } \\
\text { Kering }\end{array}$ & Persentase & $\begin{array}{l}\text { Mata } \\
\text { Normal }\end{array}$ & Persentase & Frekuensi & Persentase \\
\hline \multicolumn{7}{|c|}{ Lama Pemakaian LK } \\
\hline 1-2 Tahun & 2 & 10,0 & 3 & 15,0 & 5 & 25,0 \\
\hline 2-3 Tahun & 6 & 30,0 & 3 & 15,0 & 9 & 45,0 \\
\hline$>3$ Tahun & 6 & 30,0 & & & 6 & 30,0 \\
\hline Total & 14 & $\mathbf{7 0 , 0}$ & 6 & 30,0 & 20 & 100 \\
\hline \multicolumn{7}{|c|}{ Lama Pemakaian LK } \\
\hline$\leq 4 \mathrm{Jam}$ & 5 & 25,0 & 2 & 10,0 & 7 & 35,0 \\
\hline$>4 \mathrm{Jam}$ & 9 & 45,0 & 4 & 20,0 & 13 & 65,0 \\
\hline Total & 14 & $\mathbf{7 0 , 0}$ & 6 & 30,0 & 20 & 100,0 \\
\hline \multicolumn{7}{|c|}{ Masa Pemakaian LK } \\
\hline 1 Bulan & & & 1 & 5,0 & 1 & 5,0 \\
\hline 3-6 Bulan & 13 & 65,0 & 5 & 25,0 & 18 & 90,0 \\
\hline$>6$ Bulan & 1 & 5,0 & & & 1 & 5,0 \\
\hline Total & 14 & $\mathbf{7 0 , 0}$ & 6 & 30,0 & 20 & 100,0 \\
\hline \multicolumn{7}{|l|}{ Tujuan } \\
\hline Kosmetik & 11 & 55,0 & 4 & 20,0 & 15 & 75,0 \\
\hline $\begin{array}{l}\text { Koreksi Kelainan } \\
\text { Refraksi }\end{array}$ & 3 & 15,0 & 2 & 10,0 & 5 & 25,0 \\
\hline Total & 14 & $\overline{70,0}$ & 6 & 30,0 & 20 & 100,0 \\
\hline
\end{tabular}


Dari data penelitian, mayoritas sampel pemakaian lensa kontak dengan lama pemakaian 2-3 tahun, yaitu berjumlah 9 responden $(70,0 \%)$ dengan mata kering berjumlah $6(30,0 \%)$ responden dan mata normal berjumlah $3(15,0 \%)$ responden . Frekuensi responden dalam lama pemakaian lensa kontak harian $>4$ jam yaitu 13 responden $(65,0 \%), 9$ responden $(45,0 \%)$ dinyatakan kering dan $4(20,0 \%)$ responden dinyatakan normal . Mayoritas dengan masa pemakaian lensa kontak 3-6 bulan sebanyak 18 responden (90,0\%), 13 responden $(65,0 \%)$ dinyatakan kering. Mayoritas tujuan sampel yang menggunakan lensa kontak sebagai kosmetik berjumlah 15 responden $(75,0 \%)$ dan 11 responden $(55,0 \%)$ diantaranya dinyatakan mata kering. Kondisi fisik air mata semua sampel dalam kondisi jernih. Pemeriksaan kimia air mata menggunakan kertas litmus merah dan biru, hasil dari pengujian kertas litmus menunjukkan bahwa $\mathrm{pH}$ dari beberapa sampel meunjukkan normal dan tidak menunjukkan hasil asam atau basa, hasil ini sejalan dengan investigasi pada mata kering menggunakan kertas indikator $\mathrm{pH}$ dimana menunjukkan tidak ada perbedaan yang signifikan dalam nilai rata-rata $\mathrm{pH}$ antara mata kering dan kelompok kontrol (masingmasing 7,46 $\pm 0,24$ dan 7,45 $\pm 0,23$ ) (Willcox dll, 2017). Kertas pH tidak dapat digunakan karna tebalnya strip $\mathrm{pH}$ tersebut dan terbatasnya kuantitas air mata yang disebabkan karena mata kering.

Tabel 2 Distribusi Frekuensi Kuantitas Air Mata pada Kelompok Case

\begin{tabular}{lll}
\hline Kategori & Frekuensi & Persentase \\
\hline Mata Normal & 6 & 30,0 \\
\hline Mata Kering & 14 & 70,0 \\
\hline Total & 20 & 100,0 \\
\hline
\end{tabular}

Berdasarkan tabel 2 pada kelompok kasus, dinyatakan mata normal sebanyak 6 responden $(30 \%)$ dan sebanyak 14 responden (70\%) mengalami mata kering.

\section{Tabel 3 Distribusi Frekuensi Kuantitas Air Mata pada Kelompok Control}

\begin{tabular}{lll}
\hline Kategori & Frekuensi & Persentase \\
\hline Mata Normal & 17 & 85,0 \\
\hline Mata Kering & 3 & 15,0 \\
\hline Total & 20 & 100,0 \\
\hline
\end{tabular}

Berdasarkan tabel 3 pada kelompok control dinyatakan mata normal sebanyak 17 responden $(85,0 \%)$ dan sebanyak 3 responden $(15 \%)$ mengalami mata kering.

\section{Tabel 4 Hasil Uji Beda}

\begin{tabular}{lc}
\hline Hasil Pengukuran & $\begin{array}{c}\text { Sig. } \\
\text { Kuantitas Airmata }\end{array}$ \\
\hline Varian yang sama diasumsikan & 0.00 \\
\hline $\begin{array}{l}\text { Varian yang sama tidak } \\
\text { diasumsikan }\end{array}$ & 0.00 \\
\hline
\end{tabular}

Dari data penelitian yang telah diuraikan bahwa untuk mengetahui perbedaan kualitas air mata pada pengguna dan non pengguna lensa kontak telah dilakukan tes schirmer dan pengisian 
lembar observasional yang menunjukkan bahwa secara statistik Uji-T Independen $r=$ $0.00<0.005$ yang menunjukkan bahwa ada perbedaan antara kuantitas air mata pengguna dan non pengguna lensa kontak.

\section{PEMBAHASAN}

Hasil penelitian pada kelompok case menunjukkan bahwa uji schirmer pada mata normal 30,0\% sedangkan pada kelompok control $85,0 \%$ dimana ada penurunan tingkat produksi air mata. Secara Statistik Uji-T Independen menunjukkan $r=0.00<$ 0.005 yang berarti ada perbedaan antara kuantitas air mata pengguna dan non pengguna lensa kontak.

Penggunaan lensa kontak dapat menyebabkan mata kering, hal itu disebabkan oleh iritasi mekanik terhadap kelenjar meibomian. Kelenjar meibomian menghasilkan lapisan lemak yang berfungsi menghambat penguapan lapisan air mata. Gangguan fungsi kelenjar meibomian menyebabkan lapisan air mata cepat menguap. Lensa kontak juga menurunkan sensitivitas permukaan mata sehingga refleks produksi lapisan air mata menurun. Peningkatan penguapan disertai penurunan produksi lapisan air mata menyebabkan sebagian besar pengguna lensa kontak mengalami mata kering (Sitompul dalam Syaqdiyah, Prihatningtias dan Saubig,2018).
Pada tabel 4.1 menunjukkan bahwa lama pemakaian harian menunjukkan bahwa pemakaian lensa kontak $>4$ jam dalam sehari memiliki risiko $1,8 \mathrm{x}$ terjadinya mata kering dibanding pemakaian $\leq 4$ jam dalam sehari. Hal ini menunjukkan bahwa lama pemakaian harian lensa kontak mempunyai hubungan dengan kejadian mata kering dimana penelitian ini sejalan dengan penelitian yang dilakukan oleh Papas et al. (2015) dengan $\mathrm{p}<0,05$ juga menunjukkan bahwa lama pemakaian harian lensa kontak mempunyai hubungan dengan kejadian mata kering (Papas dalam Gultom,2017). Sedangkan mata kering akibat masa pemakaian 3-6 bulan ada $13(65,0 \%)$ sampel.

Sebuah penelitian lain juga dilakukan dengan $\mathrm{p}<0,05$. Hasilnya adalah didapatkan adanya hubungan yang cukup bermakna antara lama pemakaian harian lensa kontak dengan kejadian mata kering. Dalam penelitian tersebut mereka menemukan bahwa para pemakai soft contact lens cenderung lebih sering mengalami mata kering dibanding pemakai rigid gas permeable Lens. Dari pemakai soft contact lens ditemukan mata kering ringan dan sedang, sedangkan pada pemakai lensa rigid gas permeable mereka menemukan bahwa $80 \%$ pemakainya memiliki mata normal dan tidak ada yang mengalami mata kering sedang. Mereka berpendapat bahwa 
hal ini terjadi akibat porsi lama pemakaian lensa kontak. Para pemakai soft contact lens cenderung memakai lensanya lebih dari lama pemakaian harian yang direkomendasikan, yaitu lebih dari delapan jam, sedangkan pemakai lensa rigid gas permeable cenderung lebih taat dalam pemakaiannya.

Hasil penelitian ini didukung dengan penelitian yang dilakukan oleh Hisan pada tahun 2016 tentang Hubungan Antara Pemakaian Lensa Kontak Terhadap Kejadian Dry Eye Syndrome Pada Siswa SMA Batik 2 Surakarta, dimana hasil penelitian ini menunjukkan bahwa jumlah siswa pemakai lensa kontak yang menderita dry eye syndrome sebanyak 50 siswa $(94,3 \%)$, sedangkan jumlah siswa bukan pemakai lensa kontak yang menderita dry eye syndrome sebanyak 29 siswa (54,7\%). Pada analisis data didapatkan nilai $\mathrm{p}=$ 0,000 yang berarti ada hubungan yang signifikan antara pemakaian lensa kontak terhadap kejadian dry eye syndrome pada Siswa SMA Batik 2 Surakarta.

Hasil penelitian Syaqdiyah (2018) tentang Hubungan Lama Pemakaian Lensa Kontak Dengan Mata Kering juga menunjukkan bahwa berdasarkan dari 50 mata yang telah dilakukan pengukuran tes Schirmer, terdapat 12 mata yang mengalami mata kering dan 38 mata dengan produksi air mata normal. Lama pemakaian lensa kontak dan mata kering memiliki hubungan bermakna $(\mathrm{p}=0,007)$ dengan kekuatan korelasi sedang $(r=$ $0,379)$.

Pada saat memakai lensa kontak, lapisan air mata prekorneal terpisah dua bagian menjadi bagian prelens dan postlens. Hal ini menyebabkan dua perubahan struktural dan fungsional yang penting, yaitu hilangnya musin pada bagian prelens dan hilangnya lapisan lemak di bagian poslens yang bertanggung jawab untuk menjaga kestabilan lapisan air mata. Terlebih lagi terpisahnya lapisan air mata ini memicu peningkatan penguapan air yang diikuti dengan peningkatan osmolaritas air mata dan pada akhirnya menyebabkan kerusakan pada permukaan mata. Semakin lama memakai lensa kontak, maka perubahan-perubahan ini akan semakin nyata dan efek dari posisi lensa kontak di prekorneal terakumulasi terusmenerus yang bermanifestasi pada semakin meningkatnya rasa tidak nyaman pada mata (Riley dalam Gultom, 2017).

\section{KESIMPULAN}

1. Secara statistik Uji-T Independen $r=$ $0.00<0.005$ terdapat perbedaan antara kuantitas air mata pengguna dan non pengguna lensa kontak.

a. Pada kelompok case secara objektif menggunakan schirmer tes dari 20 sampel sebanyak 14 orang $(70,0 \%)$ mengalami mata kering. 
b. Pada kelompok control secara objektif menggunakan schirmer tes dari 20 sampel sebanyak 3 orang $(15,0 \%)$ mengalami mata kering.

2. Berdasarkan lama pemakaian lensa kontak tahunan dan harian terdapat 14 $(70,0 \%)$ orang mengalami mata kering dengan pemakaian tahunan 2-3 tahun dan > 3tahun berjumlah $6(30,0 \%)$ orang dan lama pemakaian harian $>4$ jam terdapat $9(45,0 \%)$ mengalami mata kering.

3. Berdasarkan masa pemakaian lensa kontak terdapat $14(70,0 \%)$ orang mengalami mata kering dengan pemakaian 3-6 bulan sebanyak 13 $(65,0 \%)$ orang.

\section{REFERENSI}

A'la RH. Studi Penggunaan Artificial Tears Pada Pasien Dry Eye Syndrome. [serial online] 2016 [dikutip 22 Jan 2019] Tersedia dari URL: http://repository.unair.ac.id/53809/13/ FF\%20FK\%2041\%2016-ilovepdfcompressed.pdf

Andini AW. Perubahan Pengetahuan Siswa Sma Tentang Lensa Kontak Sebelum Dan Sesudah Edukasi. [serial online] 2017 [dikutip 03 Feb 2019] Tersedia dari URL: http://eprints.undip.ac.id/61939/3/BAB 2.pdf.

Away N.I. Dry Eyes [serial online] 2017 [dikutip 24 Februari 2019] Tersedia dari URL: https://www.scribd.com/document/394 360700/Laporan-kasus

Elvira. Wijaya NV. Penyakit Mata Kering. [serial onine] 2018 [dikutip 02 Des 2018] Tersedia dari URL:
http://www.kalbemed.com/Portals/6/1 0 262CMEPenyakit\%20Mata\%20Kering.pdf Ghiffari MIH. Pengaruh Konsumsi Kopi Terhadap Sindroma Mata Kering (Dry Eye). [serial online] 2017 [dikutip 25 Jan 2019] Tersedia dari URL: http://repository.umy.ac.id/bitstream/h andle/123456789/23180/6.BAB\%20II. pdf? sequence $=6 \&$ isAllowed $=y$.

Gultom MTH. Hubungan Lama Pemakaian Soft Contact Lens Dengan Kejadian Sindrom Mata Kering. [serial online] 2017 [dikutip 28 Jan 2019] Tersedia dari URL: http://repositori.usu.ac.id/bitstream/han dle/123456789/4714/140100178.pdf?s equence $=1 \&$ is Allowed $=\mathrm{y}$.

Hidayat, A. A. (2010). Metode Penelitian Kebidanan dan Analisis Data. Jakarta: Salemba Medika.

Hisan C. Hubungan Antara Pemakaian Lensa Kontak Terhadap Kejadian Dry Eye Syndrome Pada Siswa Sma Batik 2 Surakarta. [serial online] 2016 [dikutip 03 Feb 2019] Tersedia dari URL: https://eprints.uns.ac.id/33342/ .

Jansen. Dampak Paparan Asap Rokok Terhadap Frekuensi Mengedip Dan Keluhan Yang Dirasakan Pada Mata Pada Pria Usia 20-40 Tahun Di Kelurahan Kesawan Medan. [serial online] 2009 [dikutip 23 Februari 2019] Tersedia dari URL: http://repository.usu.ac.id/handle/1234 56789/16739

Kurniawati AT. Hubungan Lama Pemakaian Lensa Kontak Terhadap Sensibilitas Kornea. [serial online] 2018 [dikutip 03 Feb 2019] Tersedia dari URL: https://ejournal3.undip.ac.id/index.php /medico/article/view/20669/19399.

Modul 3 IACLE,2000. Fitting Lensa Kontak. Australia : Internasional Association of Contact Lens Educators.

Notoatmodjo S. 2014. Metodologi Penelitian Kesehatan. Edisi Revisi 2. Jakarta : Rineka Cipta. 
Nursalam.2003.Konsep Dan Penerapan Metodologi Penelitian Ilmu Keperawatan. Jakarta : Salemba Medika.

Pietersz LE. Sumual V. Rares L. Penggunaan Lensa Kontak dan Pengaruhnya Terhadap Dry Eyes Pada Mahasiswa Fakultas Ekonomi Universitas Sam Ratulangi. [serial online] 2016 [dikutip 13 Des 2018] Tersedia dari URL: https://ejournal.unsrat.ac.id/index.php/ eclinic/article/download/12289/11869.

Purnama DAM. Perbedaan Ph Darah Tali Pusat Pada Bayi Asfiksia Dan Tidak Asfiksia Di Rsud Margono Soekardjo Purwokerto Tahun 2014. [serial online] 2014 [dikutip 28 Juni 2019] Tersedia dari URL : http://ejournal.stikesmukla.ac.id/index. php/involusi/article/view/152

Rahman A. Hubungan Uji Schirmer dan Uji Tear Break Up Time Dengan Kadar Hba1c Pada Pasien Diabetes Melitus Tipe 2 Di Rumah Sakit Pertamina Bintang Amin Bandar Lampung. [serial online] 2018 [dikutip 26 Jan 2019] Tersedia dari URL: http://digilib.unila.ac.id/32735/20/SKR IPSI\%20TANPA\%20BAB\%20PEMB AHASAN.pdf

Riset Kesehatan Dasar. 2013. Badan Penelitian Dan Pengembangan Kesehatan. Jakarta: Kementrian Kesehatan Republik Indonesia.

Rolando M. DRY EYE: DIAGNOSTIC TEST TEMPLATE. [serial online] 2006 [dikutip 10 Maret 2019] Tersedia dari URL: https://www.tearfilm.org/dewsreport_ German/pdfs/Ferning\%20Tear\%20fern ing\%20test $\% 20 \% 5 \mathrm{BTFT} \% 5 \mathrm{D} \% 20$ (Ro lando).pdf

Sastroasmoro, Sudigno. 2008. Dasar-Dasar Metodologi Penelitian Klinis. Jakarta: Sagung Seto.

Sinaga H. Wahdini S. Tingkat Perilaku Mahasiswa Fkui Mengenai Pemakaian Lensa Kontak Dalam Pencegahan Infeksi Achantamoeba Spp. Dan Hubungannya Dengan Karakteristik
Mahasiswa. [serial online] 2014 [dikutip 24 Jan 2019] Tersedia dari URL:

https://anzdoc.com/download/sinagah-1-wahdini-s-2.html

Stapleton F, Garrett Q, Chan C, Craig JP. The epidemiology of dry eye disease. In: Chan C, editor. Dry eye: A practical approach, essentials in ophthalmology. Berlin

Sudjana.2002. Metode Statistika. Bandung: Tarsito, h. 239-240.

Sugiyono. 1997. Statistika Untuk Penelitian, Bandung:Alfabeta, h. 150153.

Sugiyono.2017. Metode Penelitian Kuantitatif, Kualitatif dan R\&D. Bandung: Alfabeta, h.85.

Sunarti, Setianingsih W. Perilaku Remaja Pengguna Lensa Kontak (Soft Lens) Dalam Perawatan Kesehatan Mata Di Smkn 3 Kota Blitar. [serial online] 2017 [dikutip 6 Des 2018] Tersedia dari URL: https://media.neliti.com/media/publicat ions/232125-behavior-of-adolescentusers-contact-len-3503c11e.pdf .

Suryani. Perbandingan Dry Eye Setelah Operasi Fakoemulsifikasi Antara Letak Insisi Temporal Dengan Letak Insisi Superior [serial online] 2018 [dikutip 23 Februari 2019] Tersedia dari URL: http://digilib.unhas.ac.id/uploaded_file s/temporary/DigitalCollection/Zjc0NT FINTQ3YjJjMjhmZWIyM2YxNzQxN WM0NDJmNTlkYmY5MmYzOQ==. pdf

Syaqdiyah WH, Prihatningtias R, Saubig AN. Hubungan Lama Pemakaian Lensa Kontak Dengan Mata Kering. [serial online] 2018 [dikutip 04 Des 2018] Tersedia dari URL: https://ejournal3.undip.ac.id/index.php /medico/article/download/20675/1940 5

Syehabudin RN. Insidensi Dry Eyes Pada Pengguna Lensa Kontak Menggunakan Tes Schirmer Dan Ocular Surface Disease Terhadap Mahasiswa Pre Klinik PSKPS Fakultas Kedokteran dan Ilmu Kesehatan UIN Syarief 
Hidayatulah. [serial online] 2017 [dikutip 13 Des 2018] Tersedia dari URL:

http://repository.uinjkt.ac.id/dspace/ha ndle/123456789/37480.

TFOS DEWS II Tear Film Report Scientific Figure on ResearchGate. [serial online] 2017 [dikutip 10 Mar 2019]. Tersedia dari URL: https://www.researchgate.net/figure/Ex amples-of-tear-ferning-patterns-forRolandos-grade-1-A-2-B-3-C-4-DFrom fig1 318575021

Utami Y, Nukman E, Azrin M. Gambaran Tingkat Pengetahuan Tentang Penggunaan Lensa Kontak Pada Siswa Dan Guru Di Sekolah Menengah Atas Negeri 1 Dan 9 Kota Pekanbaru. [serial online] 2016 [dikutip 22 Januari 2019] Tersedia dari URL: https://media.neliti.com/media/publica
tions/186378-ID-gambaran-tingkatpengetahuan-tentang-pen.pdf.

Wakarie PR, Rares L. Perbandingan Produksi Air Mata Pada Pengguna Lensa Kontak Dengan Yang Tidak Menggunakan Lensa Kontak. [serial online] 2014 [dikutip 02 Des 2018] Tersedia dari URL: https://ejournal.unsrat.ac.id/index.php/ eclinic/article/view/3613.

Willcox MDP. TFOS DEWS II Tear Film Report [serial online] 2017 [dikutip 1 Juli 2019] Tersedia dari URL: https://www.ncbi.nlm.nih.gov/p mc/articles/PMC6035753/

Willy T.Alodokter. Mata Kering. Diperbaharui 4 Agustus 2018. Di akses 07 Feb 2019. Tersedia dari URL:

https://www.alodokter.com/mat a-kering 